live in cities, and they will miss all Metis - who make up one third of Canada's Aboriginal population."

Mary Simon, president of Inuit Tapiriit Kanatami, believes the Inuit voice is lost. "Inuit have been consistent in seeking high level representation at Parliamentary standing committees, and more recently in asking that an Inuit specific annex be included to the Canadian pandemic plan. Without someone on the network who understands these realities, we feel our issues will not get addressed."

Barker notes that both the Assembly of First Nations and Inuit Tapiriit Kantami first began pushing for representation when the notion of creating the network emerged in 2005. Four years later, Barker says Ottawa "is still sitting on the fence. The focus is on consultation with us, not on inclusion. And that's very dangerous."

Barker also believes the Assembly of First Nations has not been invited to join the network "because there seems to be an opinion the topics we bring are political."

Although Métis National Council Minister for Health David Chartrand declined to discuss the network, he recently accused Ottawa of failing to consult Métis leaders on pandemic (H1N1) 2009.

Health Canada, meanwhile, referred written questions about the network to PHAC, where a request for an interview with Butler-Jones was declined. In a written statement, PHAC spokesman Robert Paterson said "Health Canada and PHAC do not have a role in selecting the PHN membership."

It's up to the federal, provincial and territorial governments to select representatives, says Paterson, who defended the federal government's decision to select senior Health Canada officials to represent Aboriginal people.

Nova Scotia Deputy Minister of Health Promotion and Protection Duff Montgomerie, who serves as the network's provincial and territorial deputy minister liaison, also defends the network's approach to handling Aboriginal matters. "There's been incredible sensitivity on First Nations issues," he says, noting that political tensions invariably influence the operation of the network. "There is always a tension between the Government of Canada and the province and territories around how First Nations are treated."

Montgomerie insists such tensions are not an impediment. "At the public health network table, it's more about keeping Canadians safe. Like what's the most important discussion we can around our populations, whether it's the Inuit, or African Canadians, or First Nations."

But the inclusion of Aboriginal groups warrants examination, Montgomerie adds. "We as a network, all of us, and I include myself, should probably work harder to ensure that we're getting direct input."

Isaac Sobol, chief medical officer of health for Nunavut, and a member of the public health network's national council, would like representatives of First Nations, Metis, and Inuit communities to be included within its struc- tures. He'd also like a formal Aboriginal advisory body to be established.

Yet the situation doesn't appear entirely bleak. Sobol says that the federal government has at times been very responsive: "The federal government has been very supportive of Nunavut's need for epidemiology studies, both with $\mathrm{H} 1 \mathrm{~N} 1$, and on previous occasions, and has provided us with teams of epidemiologists on any occasion when we have requested their assistance."

Margo Greenwood, director of the National Collaborating Centre for Aboriginal Health, which is funded by PHAC, also thinks the time has come to formally include Aboriginal organizations on the network's council. "We need to have a voice, she says. "In facing emerging challenges, we have to have voices there. H1N1 is a really good example of why." — Paul Webster, Toronto, Ont.

DOI:10.1503/cmaj.109-3073

\title{
Banning 'magic mint' could slow research
}

Previously published at www.cmaj.ca

$S$ alvia divinorum can beam you to Mars. It can eradicate gravity. It can show you things that will make you howl with laughter and things that will make you scream in fear. But it only does these things in your head and only for about 15 minutes.

Millions of people have embarked on short-haul head trips after smoking Salvia divinorum, a plant from the mint family. Thousands have posted their hallucinogenic journeys on YouTube. In one video, viewed some two million times, a young woman says her mouth is falling off.

Some lawmakers believe Salvia divinorum, a.k.a. 'magic mint' or 'diviner's sage,' is dangerous. About a dozen countries have banned it, including Australia and Belgium. Selling it in parts of the United States will also earn you a fine and jail time. But it's legal in

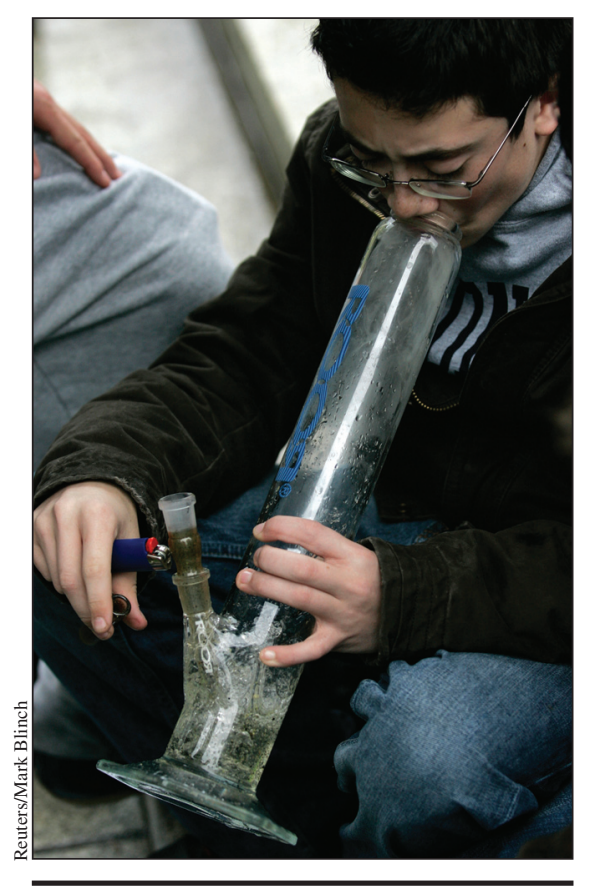

Salvia divinorum is smoked in a bong and induces short, vivid hallucinations. 
Canada. In some Canadian cities, a shop selling bongs is likely to have a cardboard sign in the window that says "Salvia sold here."

Though many politicians have the plant on their not-in-my-jurisdiction lists, there is no scientific data to suggest the plant's active ingredient, Salvinorin A, has any long-term effects. Some researchers studying the plant which may prove useful in treating mental illness - are worried that bans may make their work more difficult. They say the herb doesn't appear to be addictive or toxic. Hospital emergency rooms aren't reporting major problems with patients suffering "bad trips" from Salvia divinorum. Nor have police made much noise about the herb.

"Health Canada has only received a limited number of communications regarding Salvia divinorum from law enforcement agencies, and none of these has advised that the use of Salvia divinorum poses any threat to public safety," Health Canada spokesman Gary Holub writes in an email.

Holub notes, however, that Health Canada is attempting to learn how many Canadians are using Salvia divinorum. It included questions about the plant in the 2008-2009 Youth Smoking Survey and the 2009 Ontario Student Drug Use and Health Survey. that the use of this substance be avoided because very little is known about the damage it may cause to the body, including the brain. There is also no way to predict how it will affect an individual with each use."

Salvia divinorum has been used by the Mazatecs in Oaxaca, Mexico, for centuries. Folk healers chew the leaves to produce mild hallucinations they believe provide spiritual guidance. In the early 1960s, Gordon Wasson, an American anthropologist, became the first person from a Western nation to take and write about the herb. In the early 1980s, a Mexican researcher isolated its active ingredient. But it wasn't until the 1990s that people began extracting that ingredient and adding it to fresh Salvia divinorum leaves.

These fortified leaves are what people buy, often over the Internet, and smoke in a bong or pipe. In the US, about 1.8 million people have tried Salvia divinorum, according to the 2008 National Survey on Drug Use and Health. As with crack cocaine, the effects upon inhalation are almost instantaneous and though short-lived, anything but mild.

"It is the most potent naturally occurring hallucinogen," says Dr. Bryan Roth, project director of the National Institute of Mental Health

\section{"What we are hoping, when we find drugs that affect human consciousness, is to use them to make better treatments for mental illness." - Dr. Bryan Roth, project director, US National Institute of Mental Health}

Health Canada is also collecting data about the herb, from national and international sources, to determine if it should be regulated.

"Very few controlled scientific studies of the physical and psychotropic effects of Salvia divinorum on humans have been carried out, and using these studies to predict the potential for addiction and abuse associated with Salvia divinorum is difficult," writes Holub. "Health Canada recommends
Psychoactive Drugs Screening Program. "It rivals LSD [lysergic acid diethylamide] in potency."

In 2002, Roth discovered that Salvinorin A had a different chemical structure than any other hallucinogen, natural or synthetic (PNAS 2002;99: 11934-9). He also found that it didn't activate the serotonin receptor responsible for the mind-bending effects of other hallucinogens. Because of its unique properties, Salvinorin A might

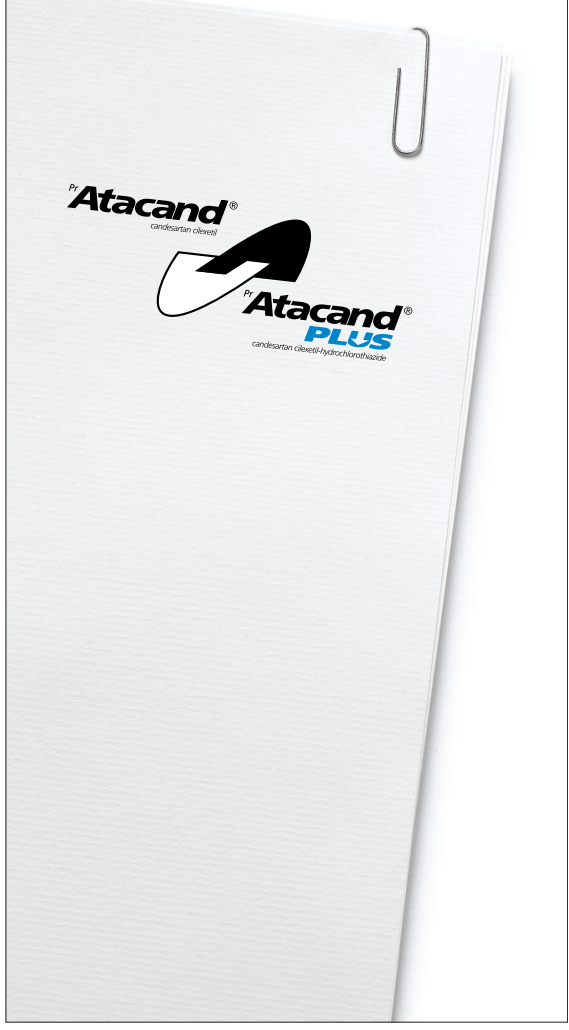

be a novel compound for use in therapies for diseases that distort perception, such as schizophrenia and bipolar disorder.

"What we are hoping, when we find drugs that affect human consciousness, is to use them to make better treatments for mental illness," says Roth, a professor at the University of North Carolina in Chapel Hill.

That research might prove challenging, however, if the US Food and Drug Administration outlaws Salvia divinorum, which Roth says is likely. Though supportive of regulating distribution, he isn't looking forward to widespread legal barriers to accessing Salvinorin A. Such laws would not only keep the herb out of the hands of teenagers hoping to visit Jupiter on purple unicorns, but also out of the labs of scientists.

"It will make subsequent studies very difficult," says Roth. "It won't make them impossible but will make it difficult to obtain for therapeutic research." - Roger Collier, CMAJ

DOI:10.1503/cmaj.109-3080 